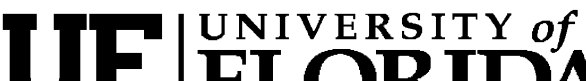 FLORIDA \\ IFAS Extension
}

ENY-255

\section{External Parasites Around Animal Facilities ${ }^{1}$}

\author{
P. E. Kaufman, P. G. Koehler and J. F. Butler²
}

\section{Flies}

Several kinds of non-biting flies can be found in and around animal facilities. These flies can be harmful to animal health and cause annoyance and discomfort. All filth flies have an egg, larva (maggot), pupa, and adult stage in their life cycle. The adult fly has 2 developed wings (the hind pair is reduced to a knobbed balancing organ).

Filth flies are usually scavengers in nature and many are capable of transmitting diseases to man. Filth flies can usually be grouped according to their habits and appearance as: house flies and their relatives; flesh flies, blow flies and bottle flies, filter flies, soldier flies, and vinegar (fruit) flies.

\section{Blow Flies and Bottle Flies}

There are many species of blow flies (Figure 1) and bottle flies which are found in and around animal facilities. The greenbottle (Figure 2), bluebottle (Figure 3), and bronzebottle flies are particularly abundant in Florida.

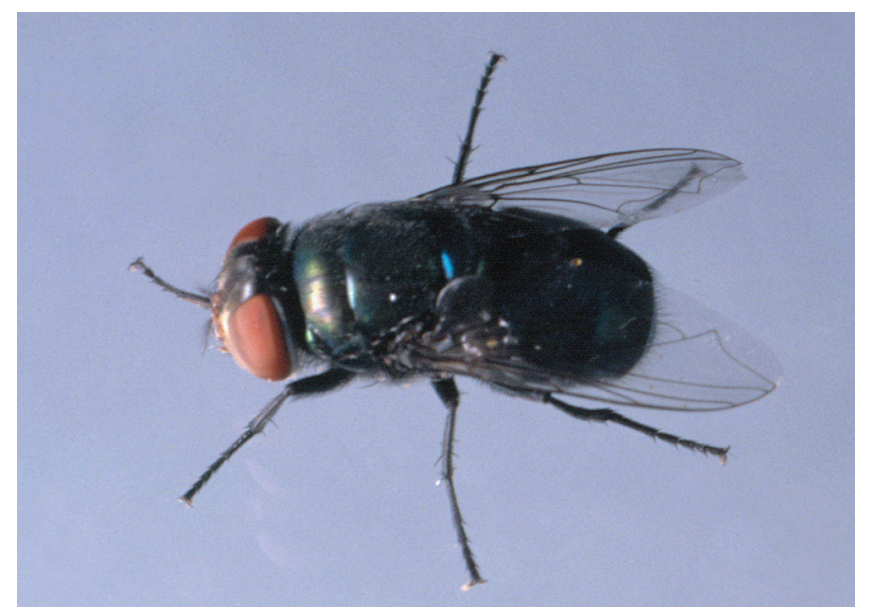

Figure 1. Blow fly. Credits: J. F. Butler, University of Florida

The blow flies and bottle flies usually have a metallic blue or green color or both on the thorax and abdomen. These flies are strong fliers and range many miles from breeding places. They are abundant during the warm summer months.

Blow flies and bottle flies can breed on dead rodents and birds in attics or wall voids of barns. They usually breed in meat scraps, animal excrement, and decaying animal matter around houses. The adult flies are active inside and are strongly attracted to

1. This document is ENY-255 (IG054), one of a series of the Entomology and Nematology Department, Florida Cooperative Extension Service, Institute of Food and Agricultural Sciences, University of Florida. Publication date: June 1993. Revised: March 2006. Please visit the EDIS Website at http://edis.ifas.ufl.edu.

2. P. E. Kaufman, assistant professor, P. G. Koehler, professor/extension entomologist, and J. F. Butler, professor, Entomology and Nematology Department, Cooperative Extension Service, Institute of Food and Agricultural Sciences, University of Florida, Gainesville, 32611.

The use of trade names in this publication is solely for the purpose of providing specific information. UF/IFAS does not guarantee or warranty the products named, and references to them in this publication does not signify our approval to the exclusion of other products of suitable composition. Use pesticides safely. Read and follow directions on the manufacturer's label. All chemicals should be used in accordance with directions on the manufacturer's label. 


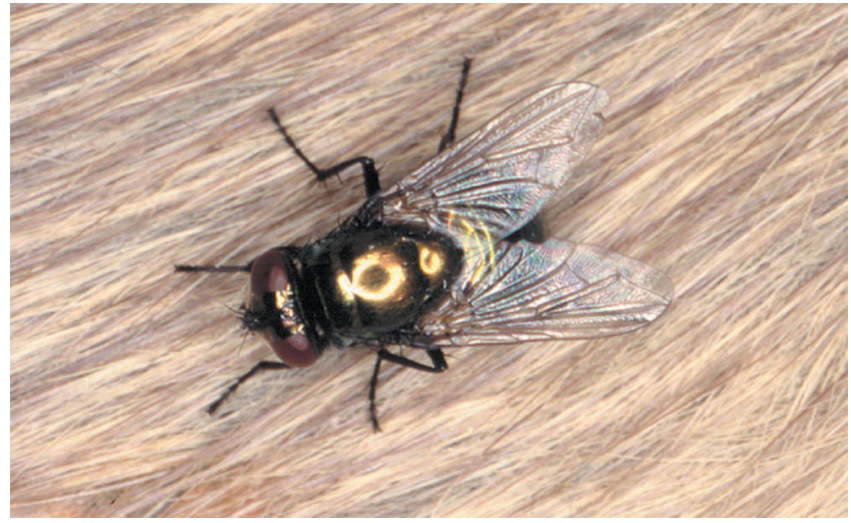

Figure 2. Greenbottle fly. Credits: J. L. Castner, University of Florida

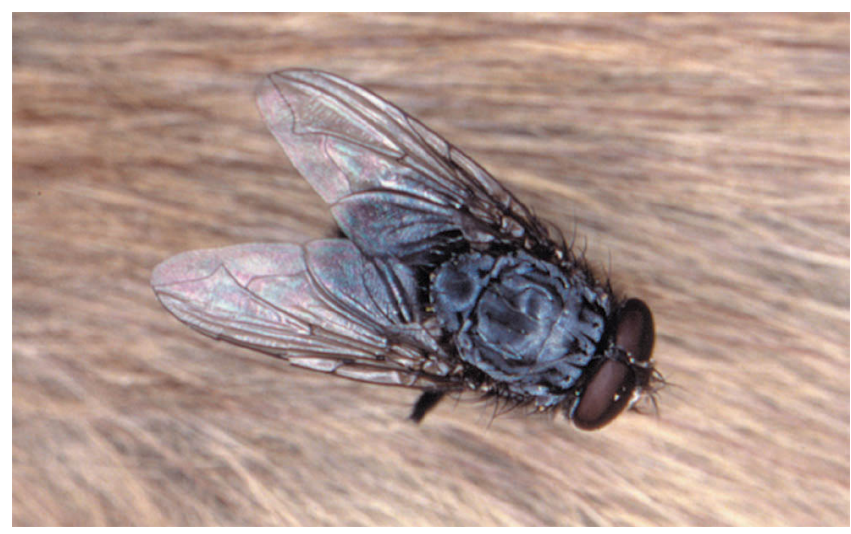

Figure 3. Bluebottle fly. Credits: J. L. Castner, University of Florida

light. The mature larvae are often a problem when they migrate from breeding areas to pupate.

Blow flies usually lay eggs on dead animals or decaying meat. Garbage cans have been known to produce 30,000 blow flies in one week. The life cycle usually lasts 9-21 days from egg to adult.

\section{Dump Flies}

Dump flies are about 1/4 inch long, black in color with a shiny thorax and abdomen. Dump flies breed in garbage and fowl excrement. The larvae are predacious on larvae of other flies.

Non-chemical control may be obtained by sanitation and destruction of breeding sites.

Larvicides, residual sprays and space sprays, may be used for chemical control.

\section{Eye Gnats}

Eye gnats (Figure 4) are small, shiny black flies about $1 / 6$ inch in length. The adults are strongly attracted to the moisture of the eyes and nose of people outdoors. In mid-summer large numbers of eye gnats persistently hover around the face causing considerable annoyance. Often eye gnats enter animal facilities through open doors or windows. They are strongly attracted to light and observed mainly on windows in large numbers.

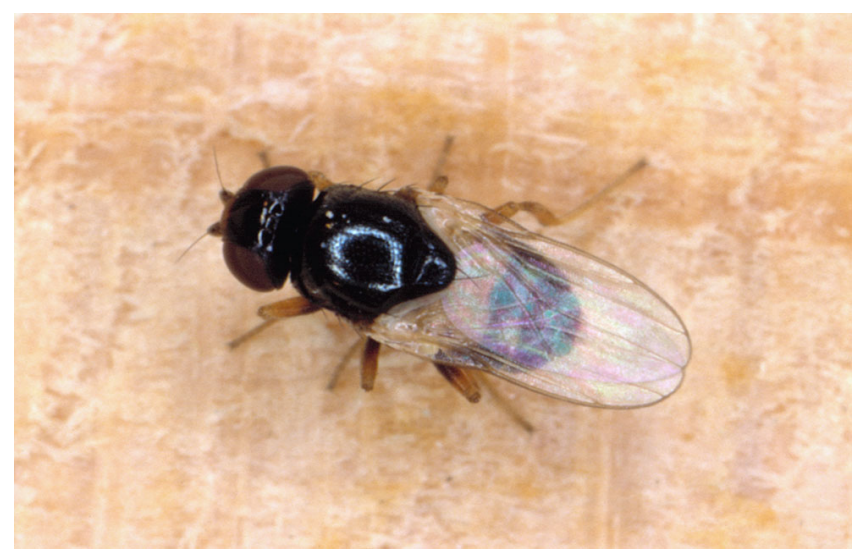

Figure 4. Eye gnat. Credits: J. F. Butler, University of Florida

Eye gnats breed in soil containing considerable organic matter, decaying vegetation and animal excrement. The life cycle varies from 7-28 days depending on the temperature and moisture.

Control of eye gnats is difficult. It is often hard to destroy breeding sites over the many acres of land where eye gnats breed. Indoors, space sprays will kill adults.

\section{House Flies}

The house fly, Musca domestica (Figure 5) is one of the most common of all insects. It is worldwide in distribution and is a pest in barns, poultry houses, food processing plants, dairies, homes, and recreation areas. It has a tremendous breeding potential and during the warmer months can produce a generation in less than two weeks. In many areas of Florida the house fly breeds continually throughout the year.

House fly eggs are laid in almost any type of warm organic material. Animal or poultry manure is an excellent breeding medium. Fermenting 


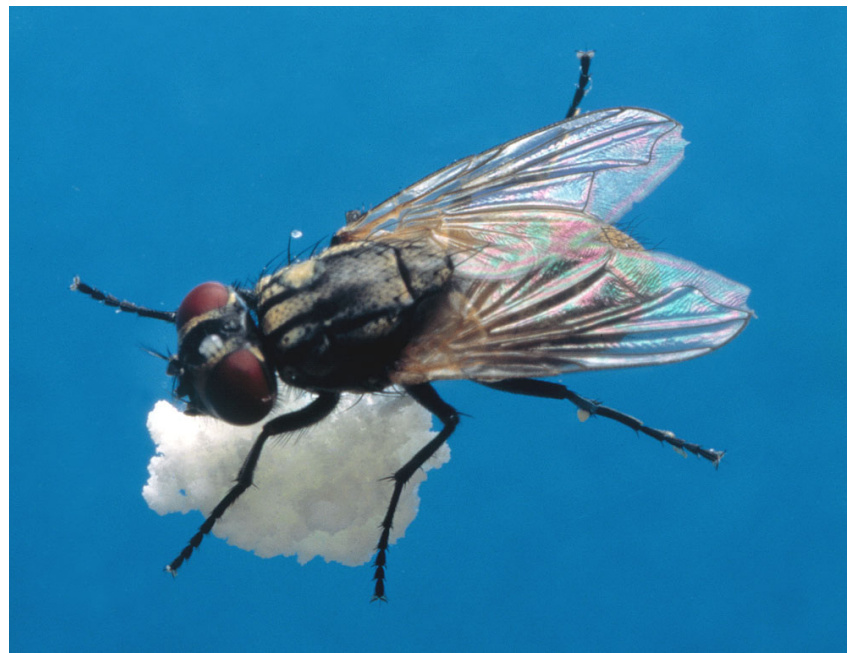

Figure 5. House fly. Credits: J. F. Butler, University of Florida

vegetation such as grass clippings and garbage can also provide a medium for fly breeding. The white eggs, which are laid in clusters of 75-100, hatch within 24 hours into tiny larvae or maggots. In 4 to 6 days the larvae migrate to drier portions of the breeding medium and pupate. The pupa stage may vary in length considerably, but in warm weather can be as short as three days.

When the adult emerges from the puparium, the wings are folded in tight pads. The house fly crawls about rapidly while the wings unfold and the body dries and hardens. Under normal conditions this may take as little as an hour. Mating occurs immediately. Under Florida conditions, a house fly may go through an entire life cycle; egg to adult in 6 to 10 days. Adult house flies live an average of 30 days. During warm weather 2 or more generations may be produced per month. Because of this rapid rate of development and the large numbers of eggs produced by the female, large populations build up.

House flies are strong fliers and can become widely distributed. Generally, however, flies are abundant in the immediate vicinity of their breeding site. Under certain conditions, they may migrate 1 to 4 miles, but are usually limited to one-half to 1 mile.

House flies feed by using sponging type mouthparts. As the fly moves from one food source to another, it samples and eats its food by regurgitating saliva onto food to liquify it. Light colored spots called fly specks are visible signs of this type of feeding. Darker fly specks, associated with house flies, are fecal spots.

\section{Hump-Backed Flies}

Hump-backed flies (Figure 6) are about 1/8 inch long with a small head and large thorax, causing the fly to have a hump-backed appearance.

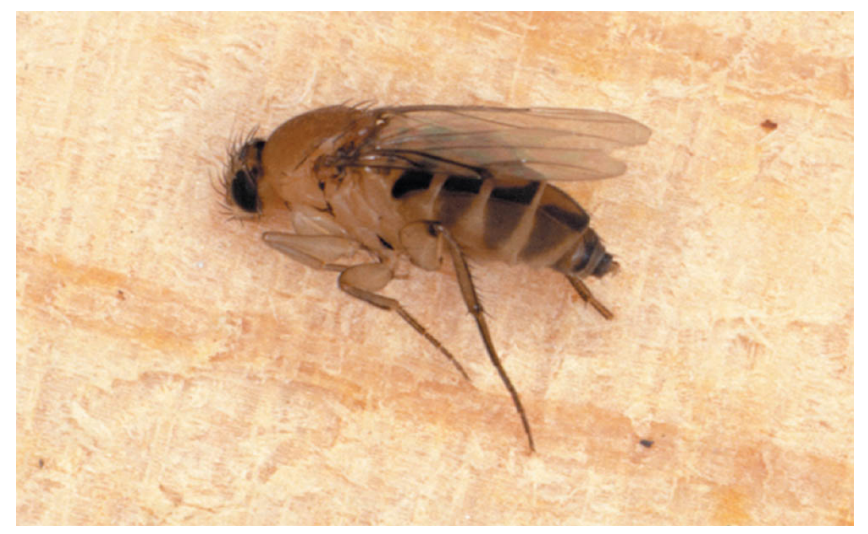

Figure 6. Humpbacked fly. Credits: J. L. Castner, University of Florida

Hump-backed flies breed in decaying vegetation, animal debris, garbage and in ant and termite nests.

Non-chemical control can be obtained by sanitation, destruction of breeding sites and moisture control.

Hump-backed flies may be chemically controlled by residual and space sprays.

\section{Moth Flies and/or Filter Flies}

Moth flies (Figure 7) are 1/16 to $1 / 8$ inch in length; light gray to tan in color. Their life cycle is 7 to 20 days.

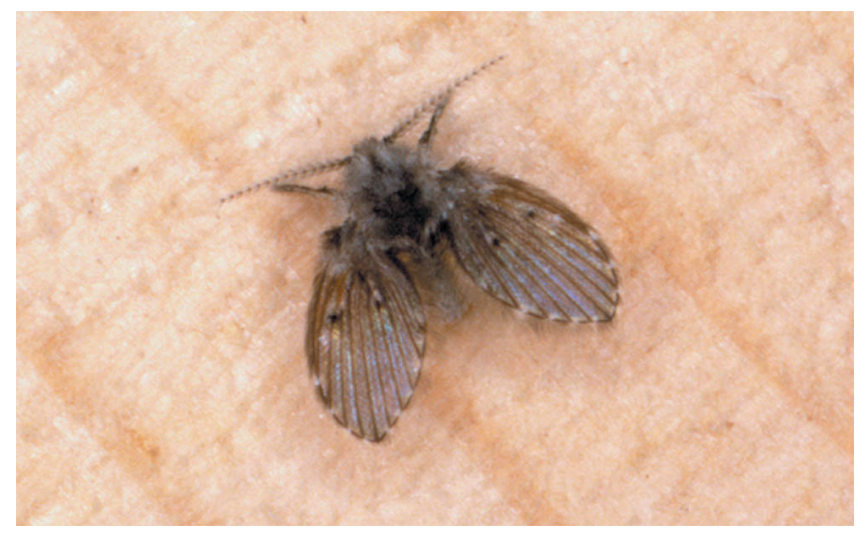

Figure 7. Moth fly. Credits: J. L. Castner, University of Florida 
Moth or filter flies breed in decomposing organic material, such as moist litter, or garbage. They can be controlled by locating and correcting the source of moisture.

Non-chemical control is obtained by sanitation and destruction of breeding sites, tight fitting garbage containers and moisture control. For a chemical control you may use larvicides, residual sprays and space sprays.

\section{Secondary Screwworm Flies}

Secondary screwworm flies (Figure 8) are about $1 / 4$ inch long, green in color, shiny abdomen and thorax with thorax marked lengthwise with three dark stripes. Their life cycle is 9 to 39 days. They breed in dead tissue of wounds in animals, fresh cut meats, and garbage.

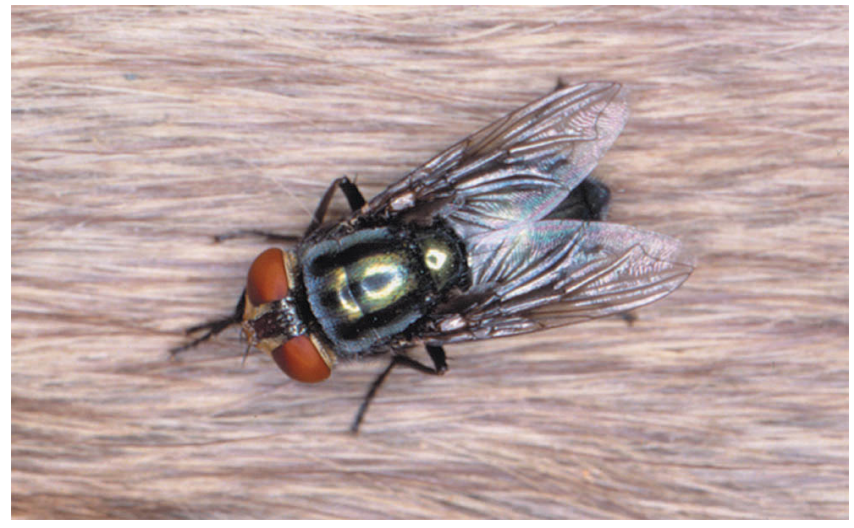

Figure 8. Secondary screwworm fly. Credits: J. L. Castner, University of Florida

Secondary screwworm flies can be non-chemically controlled by sanitation and destruction of breeding sites.

Chemical control may be obtained by residual and space sprays.

\section{Soldier Flies}

The soldier fly (Figure 9) is a widespread pest which occasionally becomes a problem in animal facilities. The adult is a large fly about 1 inch long with 2 large translucent areas on the abdomen. The fly behaves like a wasp and is similar in appearance to a mud-dauber wasp. The larvae prefer to feed on human or animal excrement, although they have also been known to breed in abandoned honey bee colonies in building walls.

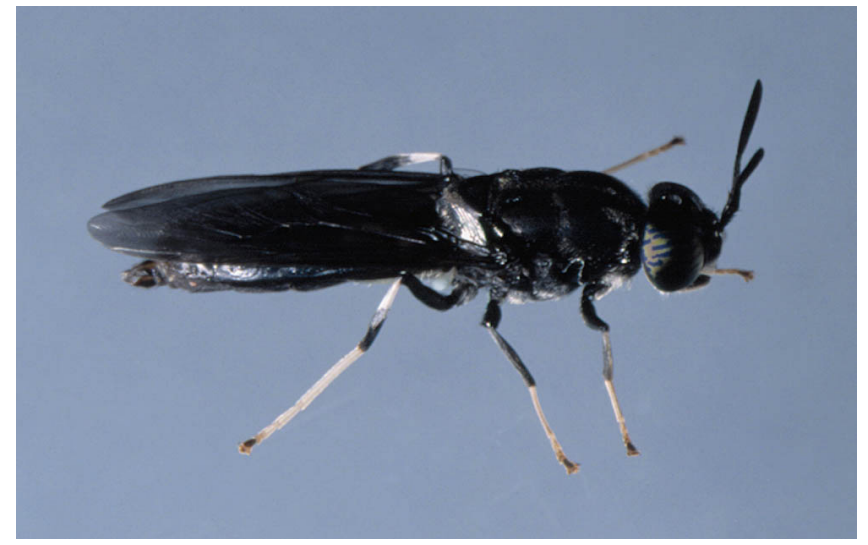

Figure 9. Soldier fly. Credits: J. F. Butler, University of Florida

\section{Stable Flies}

The stable fly (Figure 10), or "dog fly," is a blood-sucking fly of considerable importance to people, pets, agricultural animals, and the tourist industry in Florida. Stable flies primarily attack animals for a blood meal, but in the absence of an animal host will also bite man.

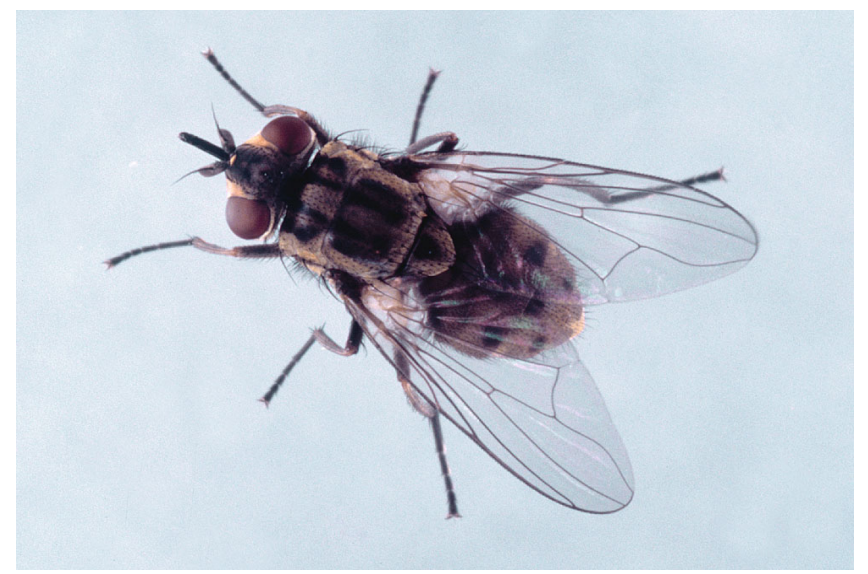

Figure 10. Stable fly. Credits: J. F. Butler, University of Florida

Adult stable flies can fly up to 70 miles from their breeding sites. The stable fly adult is similar to the house fly in size and color, however, the stable fly has a long bayonet-like mouthpart for sucking blood. Unlike many other species of flies, both male and female stable flies blood feed.

The stable fly breeds all year in Florida although peak populations occur from August through October.

Stable fly bites are extremely painful to both man and animal. When hungry, stable flies are quite persistent and will continue to pursue a blood meal 
even after being swatted at several times. Although the bite is painful, there is little irritation after the bite, and few people exhibit an allergic reaction to the bites.

The most practical and economical method for reducing stable fly populations is the elimination or proper management of breeding sources. It is important to remember that stable flies cannot develop in dry materials.

Stable flies breed in three principal types of material:

- Green vegetation (e.g. green chop, silage, crop residues, and cut grass),

- Seaweed and Bay grass deposits and

- Animal manure.

\section{Vinegar (Fruit) Fly}

Fruit flies (Figure 11) are nuisance pests and contaminators of food. Fruit flies usually breed in fruit, dirty garbage containers, or slime in drains.

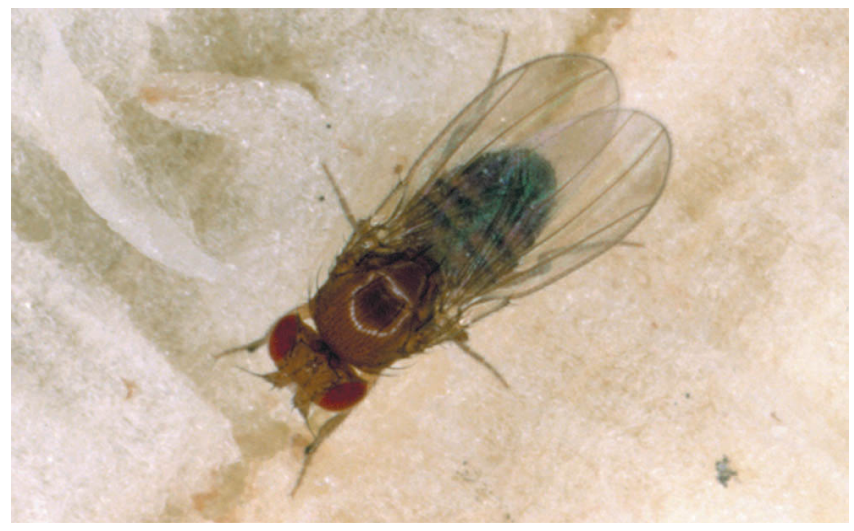

Figure 11. Fruit fly. Credits: J. L. Castner, University of Florida

Each adult lays about 500 eggs which hatch and the larvae mature to adults in 9-12 days. These flies are readily attracted to fruit, vegetables, and soda bottles or cans.

\section{Fly Control}

Regardless of advancements in chemical control, sanitation is still the best method of controlling filth flies in and around the farm. Flies seek breeding places where garbage, animal droppings or vegetation residues accumulate. Locate and thoroughly clean such places. Dry, spread or dispose of dog, cat, or other animal excrement. Do not let garbage accumulate in the open and make sure garbage cans have sound bottoms and tight fitting lids.

Good fitting screens on windows and doors are essential in barring flies from dairy barns, milk rooms, and food processing areas. Try to make all screen doors open outward. In areas with high humidity such as exists in Florida, screens last longer when made of copper, aluminum or plastic.

Galvanized screens deteriorate rapidly.

To kill flies in and around farm buildings apply a residual spray, an insecticide bait, or a larvicide to the breeding areas.

\section{Mosquitoes}

Mosquitoes (Figure 13) can be an annoying, serious problem in throughout Florida. Their attacks on farm animals can cause weight loss and decreased milk production. Some mosquitoes are capable of transmitting diseases such as malaria, yellow fever, and dengue to man, encephalitis to man and horses, and heartworm to dogs.

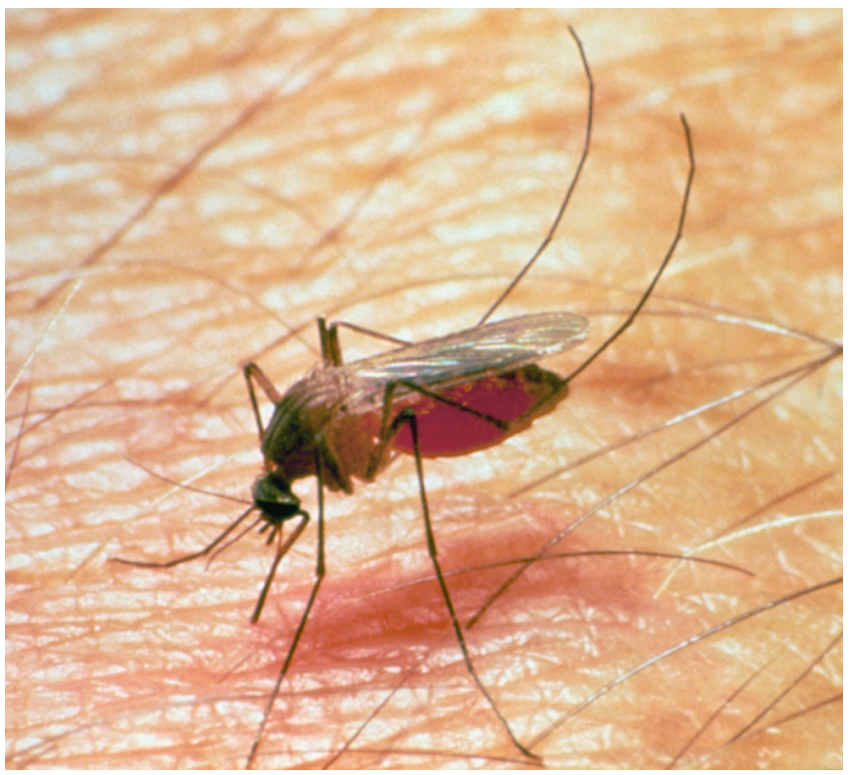

Figure 12. Mosquito. Credits: J. F. Butler, University of Florida

Mosquitoes are insects with long slender bodies, narrow wings with a fringe of scales on the edge of 
the wing and along the veins, and long, thin legs. The females have firm mouthparts, usually well-adapted for piercing skin and sucking blood. The males cannot blood feed but both sexes feed on nectar of various plants.

The life cycle of a mosquito consists of four stages: egg, larva, pupa, and adult. Depending upon mosquito species, the eggs may be laid singly or in rafts, deposited in water, on the sides of containers where water will soon cover, or on damp soil where they can hatch when flooded by rainwater or high tides.

The elongated eggs, about $1 / 40$ inch long, are laid in batches of 50 to 200 and one female may lay a batch every few days. In warm water, the eggs of most species hatch in two or three days. However, some eggs require a drying period, remaining dormant for months, hatching soon after water contacts them.

Mosquitoes show considerable variation in their preferred hosts. Some species feed on cattle, horses, or other domestic animals while others prefer man. A few species feed only on cold-blooded animals and some live entirely on nectar or plant juices. Some are active at night and others only during the daytime.

\section{Keys to Pesticide Safety}

1. Before using any pesticide, stop and read the precautions.

2. Read the label on each pesticide container before each use. Heed all warnings and precautions.

3. Store all pesticides in their original containers away from food or feed.

4. Keep pesticides out of the reach of children, pets and livestock.

5. Apply pesticides only as directed.

6. Dispose of empty containers promptly and safely. Recommendations in this guide are for guidelines only. The user must insure that the pesticide is applied in strict compliance with label directions.
The Food and Drug Administration has established residue tolerances for certain insecticides in the meat of certain animals. When these and other approved insecticides are applied according to recommendations, the pests should be effectively controlled and the animals' products will be safe for food.

The improper use of insecticides may result in residue in milk or meat. Such products must not be delivered to processing plants.

To avoid excessive residues, use the insecticides recommended at the time recommended and in the amounts recommended.

\section{Selected References}

Catts, E. P and G. R. Mullen. 2002. Myiasis (Muscoidea, Oestroidea), In: Medical and Veterinary Entomology, (G. R. Mullen and L. A. Durden, Eds.), pp. 318-348. Elsevier Science, San Diego, CA.

Cilek, J. E. 2002. Attractiveness of beach ball decoys to adult Stomoxys calcitrans (Diptera: Muscidae). J. Med. Entomol. 39: 127-129.

Hogsette, J. A. and J. P. Ruff. 1985. Stable fly (Diptera: Muscidae) migration in Northwest Florida. Environ. Entomol. 14: 170-175.

Jones, C. J., J. A. Hogsette, R. S. Patterson, D. E. Milne, G. D. Propp, J. F. Milio, L. G. Rickard and J. P. Ruff. 1991. Origin of stable flies (Diptera: Muscidae) on West Florida beaches: Electrophoretic analysis of dispersal. J. Med. Entomol. 28: 787-795.

Knapp, F. W. 1985. Arthropod pests of horses. In: Livestock Entomology (R. E. Williams, R. D. Hall, A. B. Broce and P. J. Scholl, eds.), pp. 297-322. Wiley, New York.

Lysyk, T. J. and R. C. Axtell. 1986. Movement and distribution of house flies (Diptera: Muscidae) between habitats in two livestock farms. J. Econ. Entomol. 76: 993-998.

Moon, R. D. 2002. Muscoid flies (Muscidae), In: Medical and Veterinary Entomology, (G. R. Mullen and L. A. Durden, Eds.), pp. 45-65. Elsevier Science, San Diego, CA. 
Pickens, L. G., E. T. Schmidtmann and R. W. Miller. 1994. How to control house and stable flies without using pesticides, pp. 1-14. USDA, Washington, DC.

Schmidtmann, E. T. 1985. Arthropod pests of dairy cattle. In: Livestock Entomology (R. E. Williams, R. D. Hall, A. B. Broce and P. J. Scholl, eds.), pp. 223-238. Wiley, New York.

Scott, J. G., R. T. Roush and D. A. Rutz. 1989. Insecticide resistance of house flies from New York dairies (Diptera: Muscidae). J. Agric. Entomol. 6: 53-64, maps. 


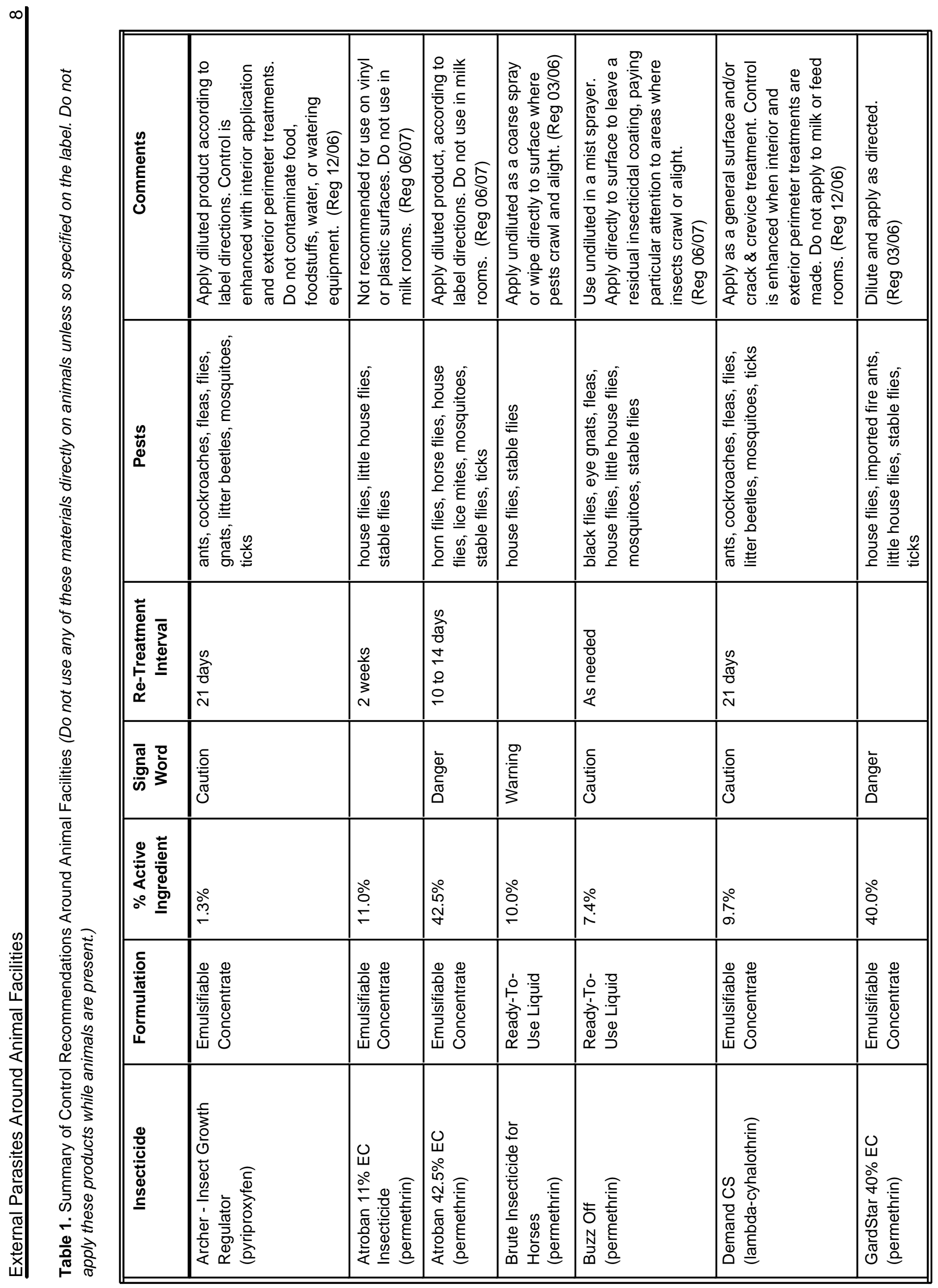




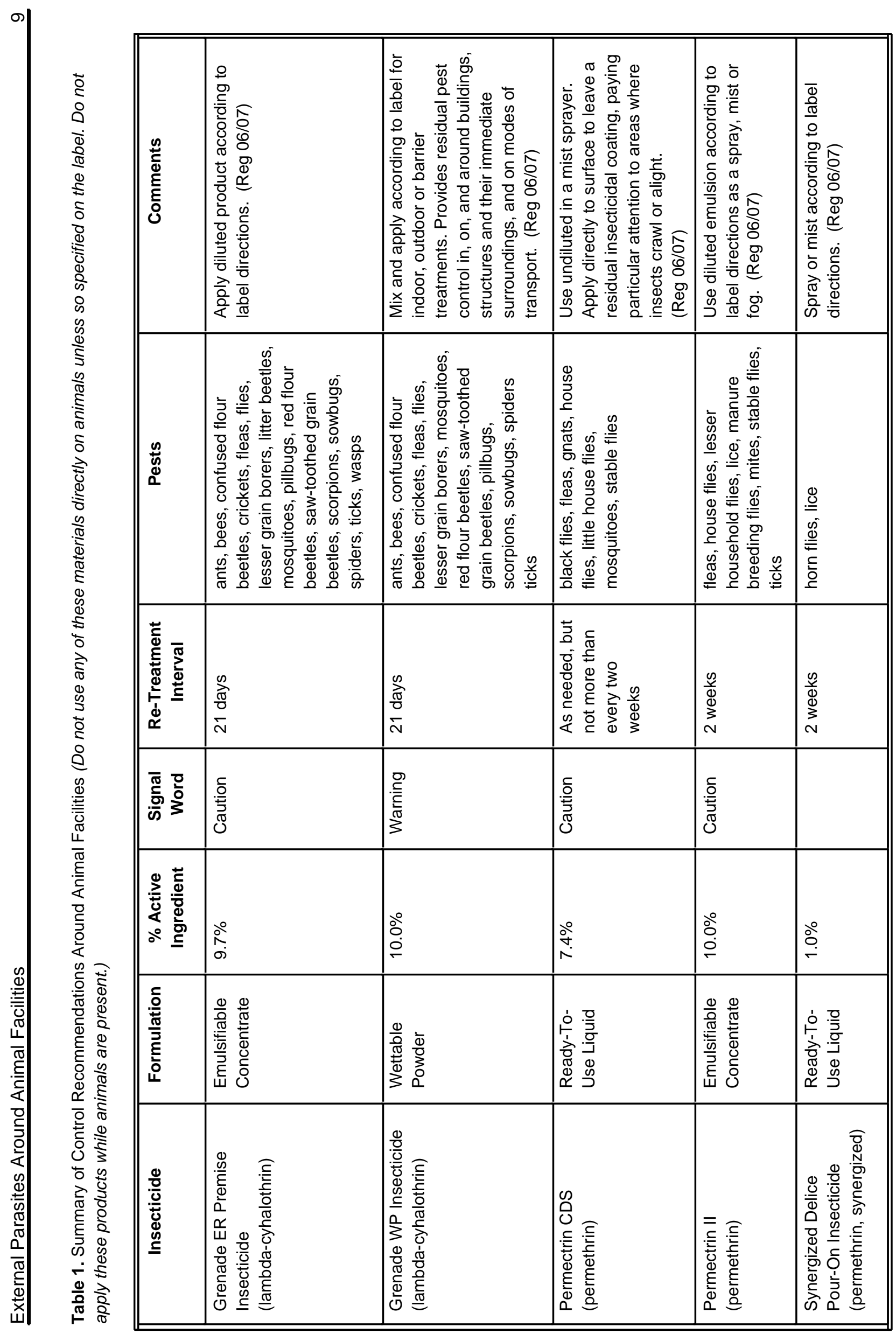




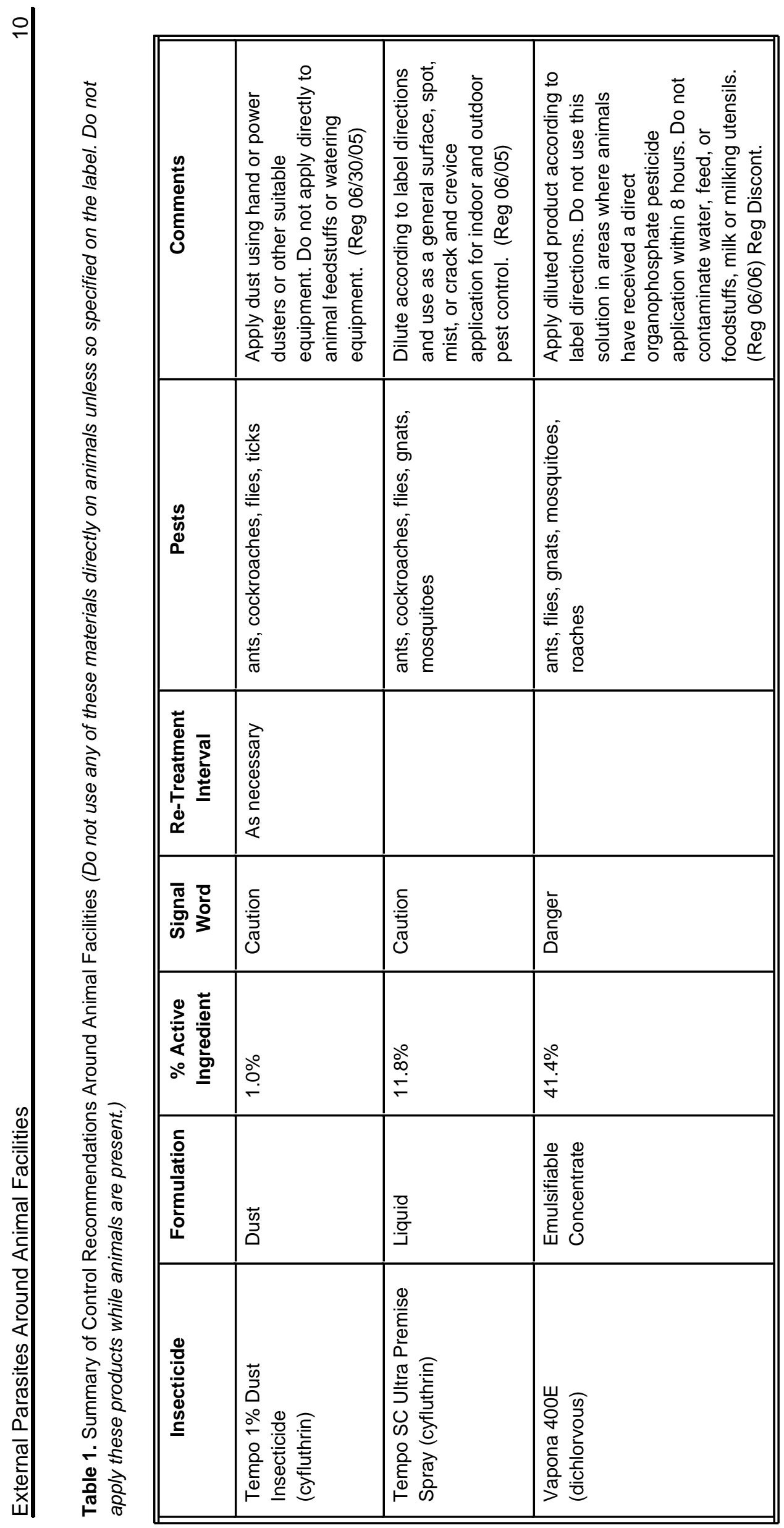

